\title{
Study of electrical properties of Polythiophene and its composites
}

\author{
Vimaldeep Kaur ${ }^{1}$, Kalpana Chauhan ${ }^{2}$ \\ ${ }^{1}$ (Department of Chemistry, Panjab University, Chandigarh-160014, India) \\ ${ }^{2}$ (Department of Physics, Bundelkhand University Jhansi, India)
}

\begin{abstract}
Abstarct : Conducting polymers are known to have significant electrical properties which can be improved by strong oxidizing power of oxidizing agents like $\mathrm{V}_{2} \mathrm{O}_{5}$. In the current study oxidative polymerization of the thiophene monomers was done to obtain Polythiophene for converting it into its composites with $\mathrm{V}_{2} \mathrm{O}_{5}$ to study their improved electrical nature. The electrical properties of pure Polythiophene, pure $V_{2} \mathrm{O}_{5}$, PTh- $\mathrm{V}_{2} \mathrm{O}_{5}$ composite 1:2 (thiophene: $\mathrm{V}_{2} \mathrm{O}_{5}$ ) and PTh- $\mathrm{V}_{2} \mathrm{O}_{5}$ composite 2:1(thiophene: $\mathrm{V}_{2} \mathrm{O}_{5}$ ) were studied by carrying out current voltage measurements. It can be stated that the increased concentration of $\mathrm{V}_{2} \mathrm{O}_{5}$ is responsible for the increased current flow through the polymer matrix. The study is explained on the basis of fact that oxidizing power leads to removal of higher number of charge carriers from the backbone thereby causing increases in current flow. Such conducting polymers have wide range of applications in the field of Metal ions detectors, molecular electronics, conductive adhesive, electrical displays, electromagnetic shields, chemical, biochemical and thermal sensors, rechargeable batteries, solid electrolytes, optical computers and ion exchange membrane.

Keywords : Composites, Conducting polymers, Polymer matrix, Polythiophene, Thiophene
\end{abstract}

\section{INTRODUCTION}

In the burgeoning field of new materials, over the last few years conducting polymers (CP) have evolved from experimental laboratory materials to fully- fledged industrial products. The use of conducting polymers has been limited in previous time due to deficiencies like their low conductivity. It has been shown that composite structures using an ordinary conducting polymer improve the electrical properties. Physico chemical manipulations of the insulating polymers offer a promise to provide a new generation of polymeric materials that exhibit the electrical and optical properties of metals or semiconductors but retain their attractive mechanical properties and processing advantages [1]. It has also shown that composite material always has advantages over homogeneous material. The study of Polythiophene (PTh) has intensified over the last three decades. It has been found that much of the relevant work was carried out in recent years. For emphasis on comparative study of synthesis, characterization and electric properties of Polypyrrole and Polythiophenes composites with tellurium oxide were prepared [2] J.M. Xu, T.S Chung et. al performed the synthesis of (3alkylthio) thiophene by $\mathrm{FeCl}_{3}$ oxidation method [3] Kabasakaloglu et.al has studied the electrochemical properties of thiophene and PTh in acetonitrile. The polarization curves and in situ measurements for PTh films have been investigated and are found to have different electrochemical properties and conduction values depending upon the type and concentration of supporting electrolyte employed, the oxidation time and applied current.

Present work covers the chemical synthesis of conducting PTh- $\mathrm{V}_{2} \mathrm{O}_{5}$ composite. Polythiophenes results from the polymerization of thiophenes [4] a sulfur heterocyclic compound that can become conducting when electrons are added or removed from the conjugated $\pi$-orbital.

\subsection{Synthesis of $\mathrm{PTh}-\mathrm{V}_{2} \mathrm{O}_{5}$}

\section{Experimental details}

Two milliliter of thiophene was taken in a titration flask containing $70 \mathrm{ml} \mathrm{CHCl} 3.9 .0$ grams of $\mathrm{FeCl}_{3}$ was weighed and $180 \mathrm{ml} \mathrm{CHCl}_{3}$ was added to this. This solution was stirred using magnetic stirrer and added to the solution of thiophene in $\mathrm{CHCl}_{3}$. To this whole mixture $\mathrm{V}_{2} \mathrm{O}_{5}$ was added in the ratio of $(1: 1,1: 2,2: 1)$, the Thiophene: $\mathrm{V}_{2} \mathrm{O}_{5}$. Then the whole mixture was stirred again After $24 \mathrm{~h}$ stirring the compound was filtered and black precipitates were washed first with $\mathrm{CHCl}_{3}$ and then with $\mathrm{CH}_{3} \mathrm{OH}$. During this procedure it was observed that color of precipitates changed from black to brown. In whole of the process thiophene monomer was oxidatively polymerized and the $\mathrm{V}_{2} \mathrm{O}_{5}$ is reduced generating $\mathrm{V}^{4+}$ centers [5] as shown in the following equation (1)

$$
\mathrm{n}(\text { Thiophene })+\mathrm{n}\left(\mathrm{V}_{2} \mathrm{O}_{5}\right) \stackrel{\mathrm{Fecl} 3 / 0-50^{\circ} \mathrm{C} / \mathrm{CCl} 4}{\rightarrow} \mathrm{PTh}+\mathrm{n}\left(\mathrm{V}_{2} \mathrm{O}_{5}\right)^{-}
$$

\subsection{Sample preparation}


The materials were dried at $60{ }^{\circ} \mathrm{C}$ for half an hour. Then compressed pellets of the synthesized materials were made employing a hydraulic press having 5 tonne load. It was ensured that the pellets used for characterizations were smooth and had uniform distribution of material. The pellets obtained were stored in clean Petri plates, to avoid any contamination. The pellets were of equal dimension. The Pellet length was maintained at $1.2 \mathrm{~cm}$ and Pellet breadth was $1 \mathrm{~mm}$ or $0.1 \mathrm{~cm}$

\subsection{Measurements}

FTIR spectra were recorded on Perkin Elmer RX-1 FTIR spectrophotometer. The spectra were obtained using $\mathrm{KBr}$ discs. The electrical properties of the samples besides I-V characterizations were carried out using ammemeter, voltmeter and standard Two Probe Techniques at room temperature $\left(25^{\circ} \mathrm{C}\right)$ with Keithley mode $6517 \mathrm{~A}$.

\section{Result and discussion}

The experimental data obtained in the present work are discussed in terms of FTIR characterization and current voltage characteristics.

\subsection{FTIR characterization}

The FTIR plot of transmittance as a function of wave number in the region $400-4000 \mathrm{~cm}^{-1}$ has been analyzed. It showed a broad peak at $2209 \mathrm{~cm}^{-1}$ corresponding to C-H antisymmetric stretching as shown in "Fig. 1". The absorption bands observed at $1320 \mathrm{~cm}-1$ and $1192 \mathrm{~cm}^{-1}$ has been ascribed to C-H bending (in plane ) and $\mathrm{C}=\mathrm{S}$ stretching respectively. The bands at $1100 \mathrm{~cm}^{-1}$ and $787 \mathrm{~cm}^{-1}$ represent in-plane and out of plane $\mathrm{C}-\mathrm{H}$ aromatic bending vibrations of thiophene rings [6] The band at $628 \mathrm{~cm}^{-1}$ represents the C-S-C ring deformation on PTh. It was further observed that the region between $200-4000 \mathrm{~cm}^{-1}$ was not clear when the spectrum was recorded using $\mathrm{KBr}$ pellets of the PTh sample. Therefore the powder was swelled using dichloromethane and the spectrum was recorded again as shown in "Fig. 2". The spectrum showed three additional peaks between 2000$3000 \mathrm{~cm}^{-1}$ at 2915,2848 and $2209 \mathrm{~cm}^{-1}$ corresponding to C-H aromatic stretching which were not clearly observable in the former spectrum. The spectra were obtained to confirm the polymer formation. The FTIR spectrum of PTh- $\mathrm{V}_{2} \mathrm{O}_{5}$ composite is shown in "Fig. 3". As from the above figure in case of $\mathrm{PTh}-\mathrm{V}_{2} \mathrm{O}_{5}$ composites, a peak present at $462 \mathrm{~cm}^{-1}$ is attributed to $\mathrm{V}-\mathrm{O}-\mathrm{V}$ stretching mode [7] which confirms the incorporation of $\mathrm{V}_{2} \mathrm{O}_{5}$ in the polymer matrix.

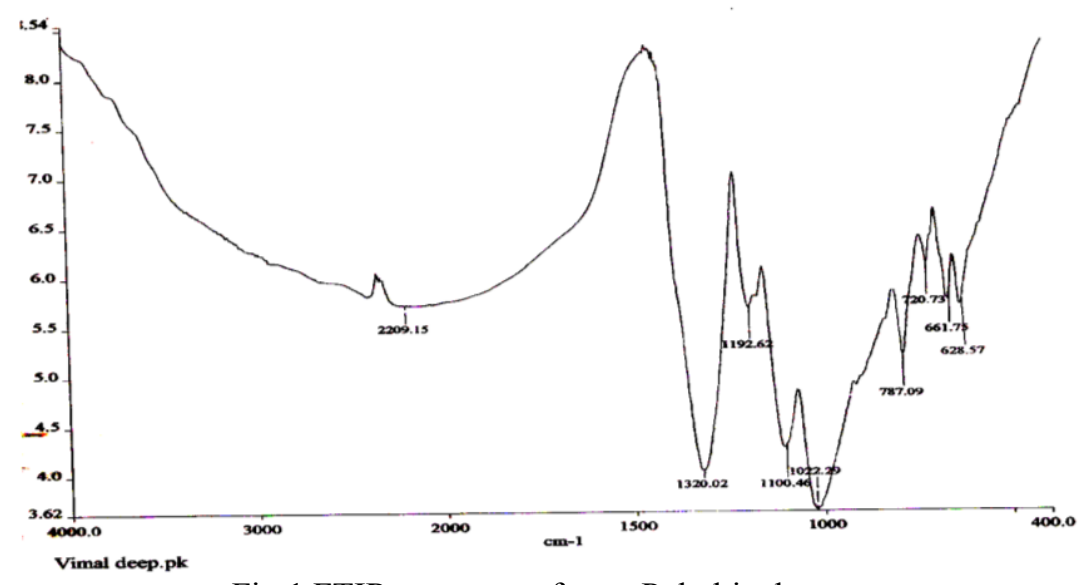

Fig 1 FTIR spectrum of pure Polythiophene

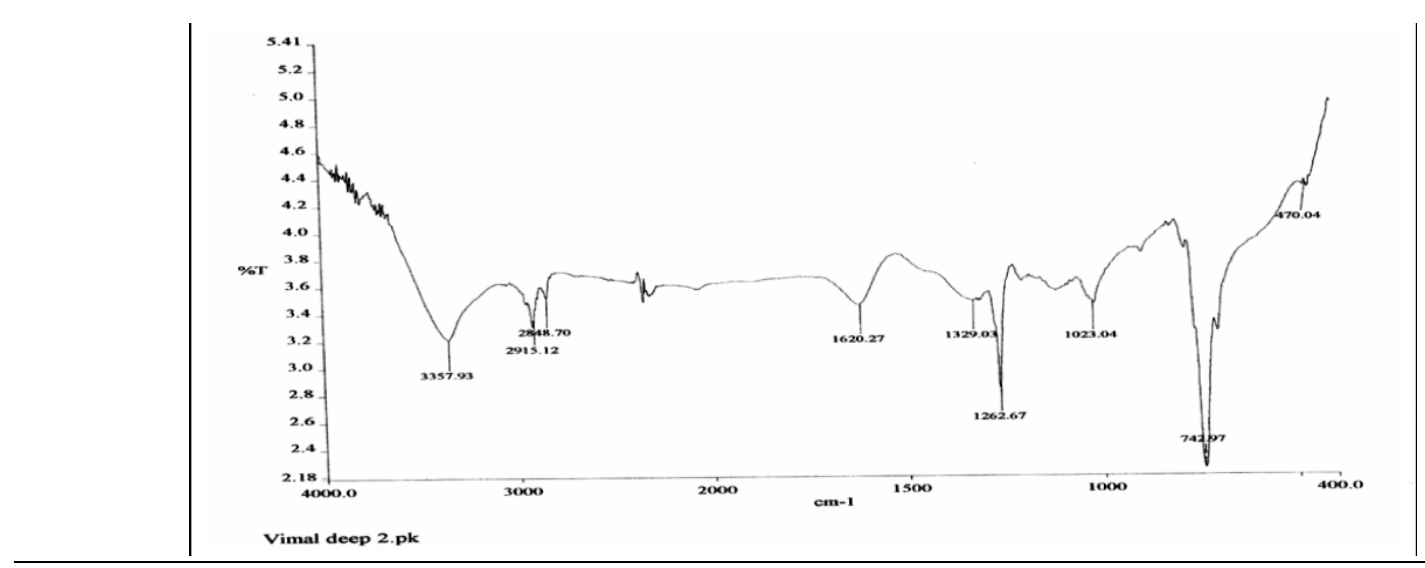


Fig. 2 FTIR spectrum of pure Polythiophene using KBr pellet swelled with dichloromethane

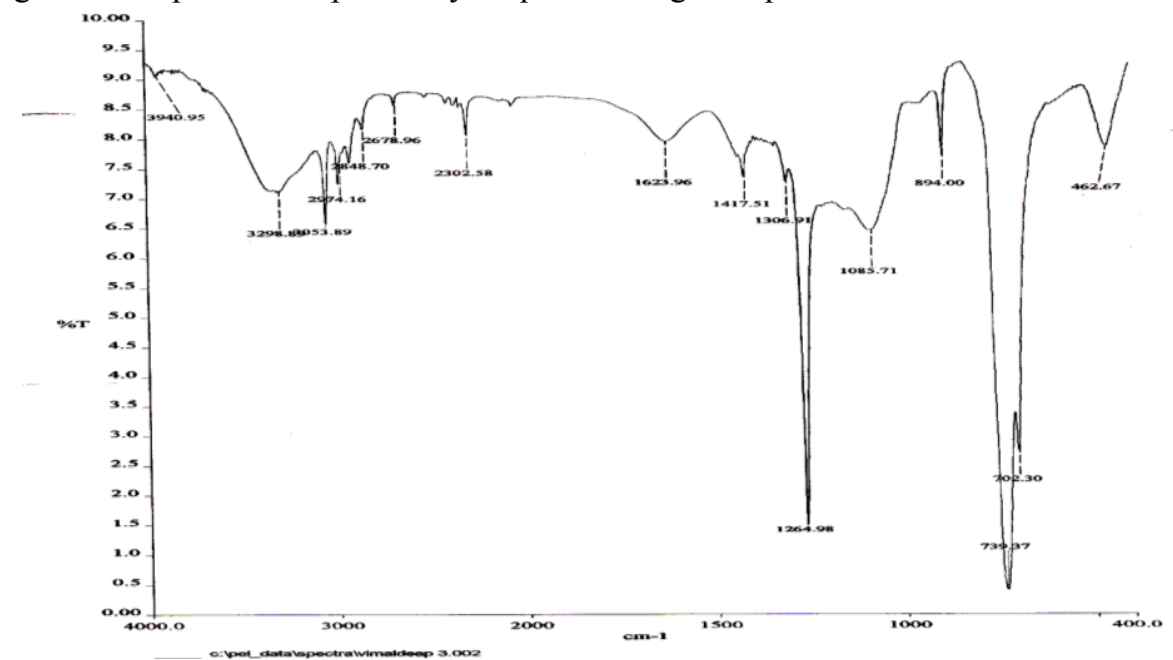

Fig 3 FTIR spectrum of PTh- $\mathrm{V}_{2} \mathrm{O}_{5}$ composite

\subsection{I-V characterization}

The electrical properties of Polythiophene were studied by carrying out current voltage measurements. The current, voltage and resistance values recorded in pure Polythiophene, pure $\mathrm{V}_{2} \mathrm{O}_{5}$, PTh- $\mathrm{V}_{2} \mathrm{O}_{5}$ composite $1: 2$ (thiophene: $\mathrm{V}_{2} \mathrm{O}_{5}$ ) and PTh- $\mathrm{V}_{2} \mathrm{O}_{5}$ composite 2:1(thiophene: $\mathrm{V}_{2} \mathrm{O}_{5}$ ). The table 3 represents the resistance and conductivity values for above data. The plots of current as a function of voltage of pure Polythiophene, Polythiophene- $\mathrm{V}_{2} \mathrm{O}_{5}(2: 1)$ and Polythiophene $-\mathrm{V}_{2} \mathrm{O}_{5}(1: 2)$ composites are shown in "Fig. 4". It is found that in general the current increases with increase in voltage. It is further observed that in the case of PTh-V2O5 (1:2) the slope is steepest followed by PTh $-\mathrm{V}_{2} \mathrm{O}_{5}$ composite (1:2). The slope of pure Polythiophene was found to be least up to a1.8 volts and then increased steeply. It can be stated from the above study that the increased concentration of $\mathrm{V}_{2} \mathrm{O}_{5}$ is responsible for the increased current flow through the polymer matrix. It seems that the strong oxidizing power of the $\mathrm{V}_{2} \mathrm{O}_{5}$ leads to removal of higher number of charge carriers from the backbone thereby causing increase in current flow. Using equation (2) and (3) the resistance and conductivity values were found. In Ohmic material the resistance is proportional to the length 1 of the sample and inversely proportional to the sample cross-section A. Where $\rho$ is the resistively, measured in $\Omega \mathrm{cm}$ (in SI units $\Omega \mathrm{m}$ ). Its inverse $\sigma=$ $\rho^{-1}$ is the conductivity. The unit of conductance is the Siemens $\left(\mathrm{S}=\Omega^{-1}\right)$. The unit of conductivity is $\mathrm{Sm}^{-1}$.

$\mathrm{R}=\rho 1 / \mathrm{A}$

$\sigma=\rho^{-1}$
(2)

(3)

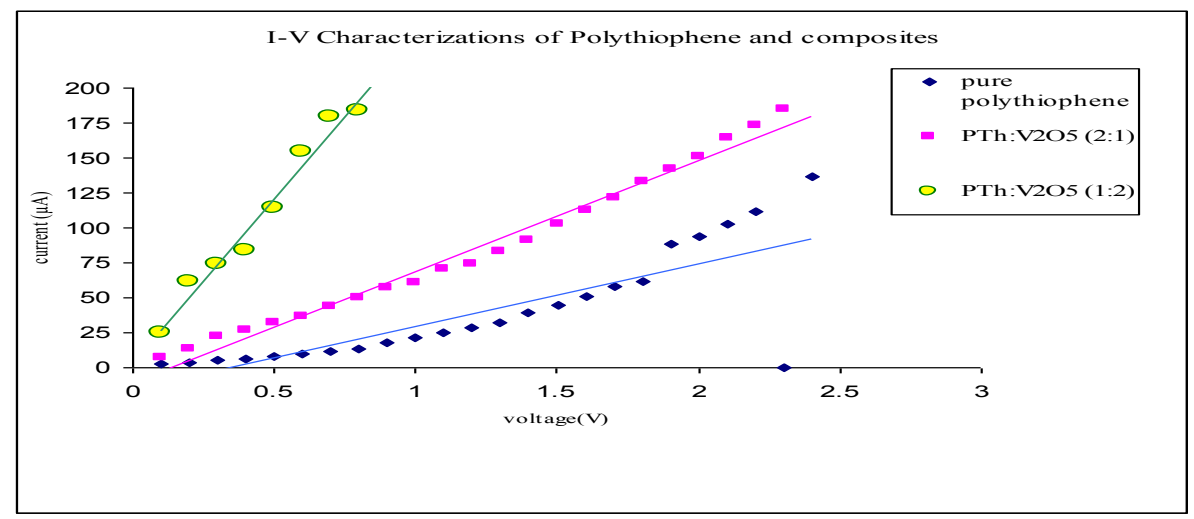

Fig.4 I-V characterizations of pure Polythiophene Polythiophene $-\mathrm{V}_{2} \mathrm{O}_{5}(2: 1)$ and Polythiophene $-\mathrm{V}_{2} \mathrm{O}_{5}(1: 2)$

Table 1Observed average Resistance and Conductivity values of pure PTh, $\mathrm{PTh}-\mathrm{V}_{2} \mathrm{O}_{5}(2: 1)$ and $\mathrm{PTh}-\mathrm{V}_{2} \mathrm{O}_{5}(1: 2)$

\begin{tabular}{|l|l|l|}
\hline Sample & Average resistance $(\Omega)$ & Conductivity $\left(\mathrm{Scm}^{-1}\right)$ \\
\hline Pure Polythiophene & 0.0640 & $1.56 \times 10^{2}$ \\
\hline Pure $\mathrm{V}_{2} \mathrm{O}_{5}$ & 0.0085 & $1.17 \times 10^{3}$ \\
\hline PTh- $\mathrm{V}_{2} \mathrm{O}_{5}(2: 1)$ & 0.014 & $7.14 \times 10^{2}$ \\
\hline PTh- $\mathrm{V}_{2} \mathrm{O}_{5}(1: 2)$ & 0.0040 & $2.5 \times 10^{3}$ \\
\hline
\end{tabular}




\section{Conclusion}

Oxidative polymerization of the thiophene monomers was done to obtain Polythiophene for converting it into its composites with $\mathrm{V}_{2} \mathrm{O}_{5}$ to study their electrical nature. The study of electrical properties of the Polythiophene- $\mathrm{V}_{2} \mathrm{O}_{5}$ composites showed that more the concentration of dopant more was the electrical conductivity. It would be interesting to carry out further research work using different dopants and even acids.

\section{References}

[1] Y. Min. and A. G. MacDiarmid, Polym. Prep., 35, 1994, 231

[2] Kowsar Majid, M.L.Singla, J mater Sci: Mater Electron DOI 10 .1007/s10854-008-98178

[3] J. M. Xu, H. S. O. Chan, S. C. Ng, T. S. Chung, Synthetic metals, 132, 2002, 63-69

[4] C. Visy, J. Lukkari, J. Kankare, Synthetic Metals, 87, 1997, 81

[5] Prakash R Somani, R. Marimuthu, A. B. Mandale, Synthetic Metals, 42, 2007, 991-3001

[6] M. Lanzi et al, Synthetic Metals, 157, 2007, 719-725

[7] P. Somani et al. Synthetic Metals, 42, 2008, 291-301 